\title{
In vitro acetaldehyde formation by human colonic bacteria
}

\author{
K Jokelainen, R P Roine, H Väänänen, $M$ Färkkilä, $M$ Salaspuro
}

\begin{abstract}
Incubation of human colonic contents with various ethanol concentrations $(2 \cdot 75-44 \mathrm{mM})$ in vitro at $37^{\circ} \mathrm{C}$ resulted in significant accumulation of acetaldehyde - a toxic and highly reactive compound. At pH 9.6, all samples produced notable acetaldehyde concentrations (58 (13) $\mu \mathrm{M}$; mean (SEM)) even from the lowest $(2 \cdot 75$ $\mathbf{m M}$ ) ethanol concentration, and the production of acetaldehyde increased linearly with rising ethanol concentration $(r=0.97 ; p<0.005)$, reaching a peak concentration of 238 (37) $\mu M$ at $44 \mathrm{mM}$ ethanol. The formation of acetaldehyde took place rapidly, as almost $50 \%$ of acetaldehyde formed during the total eight hour incubation was detectable after one hour, and $75 \%$ of the total after four hours. Maximal acetaldehyde production from $22 \mathrm{mM}$ ethanol occurred at pH 9.6 (160 (35) $\mu \mathrm{M}$ ) but appreciable concentrations were also seen at pH 7.4 (110 (38) $\mu M)$ and pH $6 \cdot 0(63(19) \mu M)$. At pH $4 \cdot 0$, by contrast, acetaldehyde formation was negligible (17 (5) $\mu \mathrm{M}$ ). 4-Methylpyrazole, a potent inhibitor of alcohol dehydrogenase, showed a decreasing effect on acetaldehyde production in vitro but first at a concentration of $100 \mathrm{mM}$. Considerable acetaldehyde production by human colonic bacteria - if it occurs also in vivo - could constitute a risk factor for rectal cancer in heavy drinkers and also provide a pathogenetic mechanism for alcohol induced diarrhoea.

(Gut 1994; 35: 1271-1274)
\end{abstract}

Alcohol consumption has been incriminated as a risk factor for oropharyngeal, ${ }^{12}$ laryngeal, ${ }^{34}$ oesophageal $^{56}$ as well as rectal $^{7-9}$ cancer. Furthermore, excessive ethanol consumption has also been related with rapid intestinal transit time and diarrhoea. ${ }^{1011}$ The pathogenetic mechanisms behind the ethanol associated gastrointestinal morbidity have, however, not been fully elucidated.

Acetaldehyde produced by colonic flora has been suggested to participate in ethanol associated carcinogenesis of the colon in rats. ${ }^{12}$ Furthermore, incubation of human faecal homogenates with ethanol has been reported to lead to accumulation of higher alcohols and other unidentified metabolites. ${ }^{13}$ Theoretically, individual differences in the susceptibility to ethanol induced organ injury might, consequently, result from differences in the metabolic products of human colonic bacteria. ${ }^{13}$ Significant in vitro production of acetaldehyde occurs also when human bronchopulmonary washings are incubated with ethanol. This acetaldehyde is thought to be formed by micro-organisms in the bronchopulmonary tract, and is suggested to participate in the pathogenesis of upper respiratory cancer. ${ }^{14}$

This study was aimed at investigating the kinetics of acetaldehyde production by human colonic bacterial flora in vitro, by incubating colonic contents obtained during colonoscopy in various ethanol concentrations at different $\mathrm{pH}$ values and for different time periods. Moreover, the effect of a well known alcohol dehydrogenase inhibitor, 4-methylpyrazole, on acetaldehyde formation by colonic contents was tested.

\section{Methods}

4-Methylpyrazole was obtained from Aldrich Chemical Co (Milwaukee, MI, USA). Colonic contents were collected from 26 patients (11 females, 15 males) undergoing colonoscopy for lower gastrointestinal symptoms. The age of the patients ranged from 24 to 67 years. Before the procedure bowel preparation was carried out in a conventional manner including a 48 hour full liquid diet, total abstinence from food on the procedure day, and colonic cleaning by drinking of four to six litres of Colonsteril, a balanced electrolyte solution (Medipolar, Oulu, Finland). During the colonoscopy, about 5-10 ml of colonic content was aspirated through the fibrescope from the sigmoid, transverse colon, and the caecum. The samples were then stored at $+4^{\circ} \mathrm{C}$ (maximum five hours) in closed vials until they were pooled and the $\mathrm{pH}$ was measured immediately before the incubation procedure. A $250 \mu \mathrm{l}$ aliquot of the colonic contents $(\mathrm{pH}$ ranging from $7 \cdot 47$ to 8.43 ) was then incubated in closed vials for two hours at $37^{\circ} \mathrm{C}$ with $250 \mu \mathrm{l}$ glycine buffer ( $\mathrm{pH} 9 \cdot 6$ ) containing different ethanol concentrations (final concentrations varying from 0 to $44 \mathrm{mM}$ ). The effect of $\mathrm{pH}$ on acetaldehyde formation was evaluated by incubating colonic contents with $22 \mathrm{mM}$ ethanol prepared either in a $1 \mathrm{M}$ citrate ( $\mathrm{pH} 4.0$ and 6.0 ), a $1 \mathrm{M}$ potassium phosphate (pH $7 \cdot 4$ ) or a $1 \mathrm{M}$ glycine $(\mathrm{pH} 9 \cdot 6)$ buffer. In addition, the velocity of acetaldehyde formation was studied by incubating three of the colonic suspensions with $22 \mathrm{mM}$ ethanol in a similar fashion for different time periods (one to 8 hours). The effect of 4-methylpyrazole on acetaldehyde production by the colonic contents in vitro was tested by incubating colonic contents with $1 \mathrm{M}$ glycine buffer (pH 9.6) containing $22 \mathrm{mM}$ ethanol and 


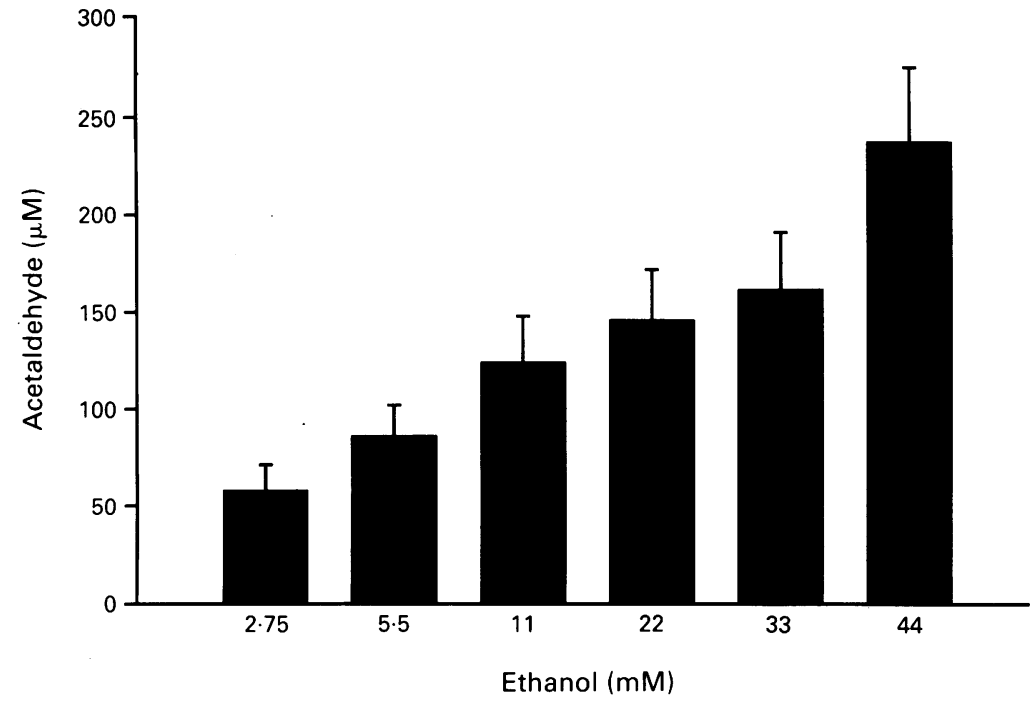

Figure 1: Acetaldehyde formation (mean $(S E M))$ by colonic contents $(n=21)$ incubated at various ethanol concentrations at $\mathrm{pH} 9.6$ at $37^{\circ} \mathrm{C}$ for two hours.

increasing drug concentrations $(0-100 \mathrm{mM})$ at $37^{\circ} \mathrm{C}$ for two hours. The acetaldehyde formed during the incubation was immediately analysed by head space gas chromatography by heating the vials to a temperature of $37^{\circ} \mathrm{C}$ as reported earlier. ${ }^{15}$ Conditions for analysis were: Column 60/80 Carbopack B/5\% Carbowax $20 \mathrm{M}, 2 \mathrm{~m} \times 1 / 8^{\prime \prime}$ (Supelco Inc, Bellefonte, PA, USA); oven temperature, $85^{\circ} \mathrm{C}$; transfer line and detector temperature, $200^{\circ} \mathrm{C}$; carrier gas flow rate $\left(\mathrm{N}_{2}\right), 20 \mathrm{ml} / \mathrm{min}$. The recovery of acetaldehyde with this method was tested and it was found to be $100 \%$.

\section{STATISTICS}

All values are expressed as mean (SEM). The dependency between ethanol concentrations and acetaldehyde formation was tested by simple linear regression analysis.

\section{Results}

At $\mathrm{pH} 9 \cdot 6$, all samples of colonic contents produced significant acetaldehyde concentrations $(58.4(12.7) \mu M$, mean (SEM)) even from a low $(2.75 \mathrm{mM})$ ethanol concentration and the amount of acetaldehyde formed increased linearly with increasing ethanol

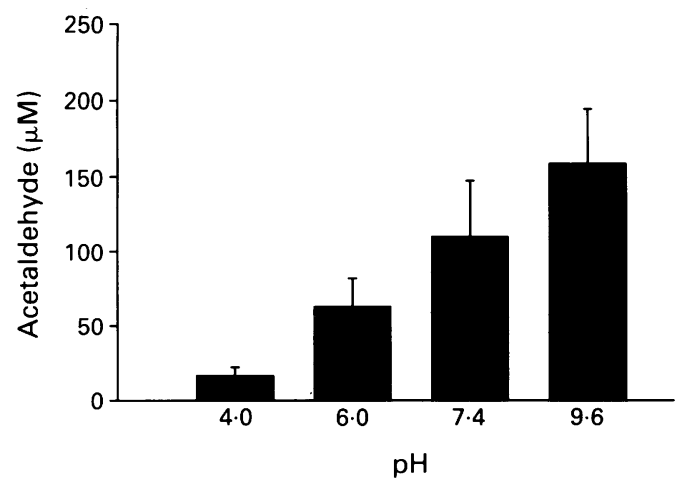

Figure 2: Acetaldehyde formation (mean (SEM)) by colonic contents $(n=10)$ incubated at $22 \mathrm{mM}$ ethanol at various $p H$ values at $37^{\circ} \mathrm{C}$ for two hours.

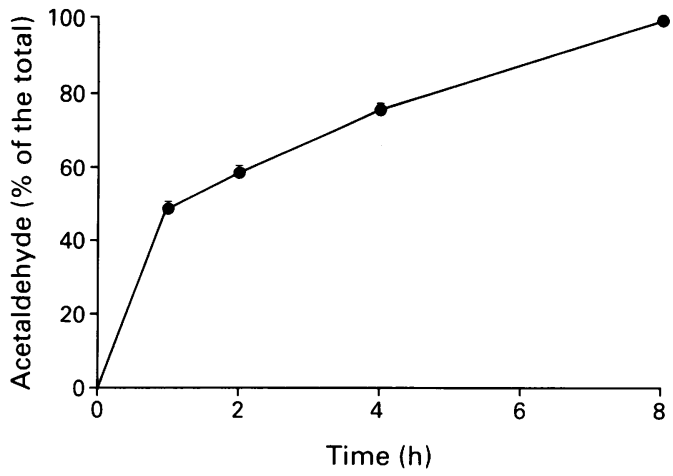

Figure 3: The velocity of acetaldehyde production by colonic contents at $22 \mathrm{mM}$ ethanol at $\mathrm{pH} 9.6$ at $37^{\circ} \mathrm{C}$, expressed as percentage (mean (SEM) of total acetaldehyde detected after eight hours incubation.

concentration $(r=0.97 ; \mathrm{p}<0.005)$, reaching a peak of 238 (37) $\mu \mathrm{M}$ of acetaldehyde at $44 \mathrm{mM}$ ethanol (Fig 1).

Maximal acetaldehyde production at $22 \mathrm{mM}$ ethanol occurred at pH 9.6 (160 (35) $\mu \mathrm{M})$ but noticeable concentrations were also seen at $\mathrm{pH}$ $7 \cdot 4(110(38) \mu \mathrm{M})$ and $\mathrm{pH} 6.0(63(19) \mu \mathrm{M})$. By contrast, at $\mathrm{pH} 4 \cdot 0$, acetaldehyde formation was almost negligible (17 (5) $\mu \mathrm{M}$ ) (Fig 2).

The formation of acetaldehyde took place rapidly as almost $50 \%$ of acetaldehyde formed during the total of eight hours incubation was detectable after one hour, and $75 \%$ of the total after four hours at $37^{\circ} \mathrm{C}$ (Fig 3).

Acetaldehyde production was significantly inhibited by 4 -methylpyrazole but first at a high concentration of the compound (at $22 \mathrm{mM}$ ethanol acetaldehyde production at $100 \mathrm{mM}$ 4-methylpyrazole 50 (10)\% of control, Fig 4).

\section{Discussion}

Acetaldehyde, the first metabolite of ethanol oxidation, is formed in the body mainly by liver alcohol dehydrogenase. To a smaller extent, ethanol is also oxidised to acetaldehyde in other tissues such as kidneys, respiratory tract, intestine, and bone marrow but until recently this metabolism has been thought to be of minor importance. ${ }^{1617}$ The finding that gastric mucosa can metabolise ethanol in significant amounts ${ }^{1819}$ has, however, again recently created interest in other sites of ethanol metabolism as well. This has in part been a consequence of the fact that acetaldehyde, as a highly reactive compound, can be linked to several organ toxic effects of ethanol, although the exact pathogenetic mechanisms behind this toxicity have so far remained obscure. ${ }^{2021}$ Recently, however, acetaldehyde has been shown to bind covalently with macromolecules and proteins thus forming acetaldehyde adducts ${ }^{22-24}$ and the formation of these adducts is proportional to the concentration of acetaldehyde. ${ }^{25}$ Adducts formed can interfere with normal cellular functions ${ }^{26}$ - that is, a human DNA repair protein, $\mathrm{O}^{6}$-methylguanine transferase, has been shown to be inhibited by acetaldehyde at nanomolar concentrations. ${ }^{27}$ Moreover, adducts also act as neoantigens with a consequent immune response. ${ }^{2829}$ Both of 


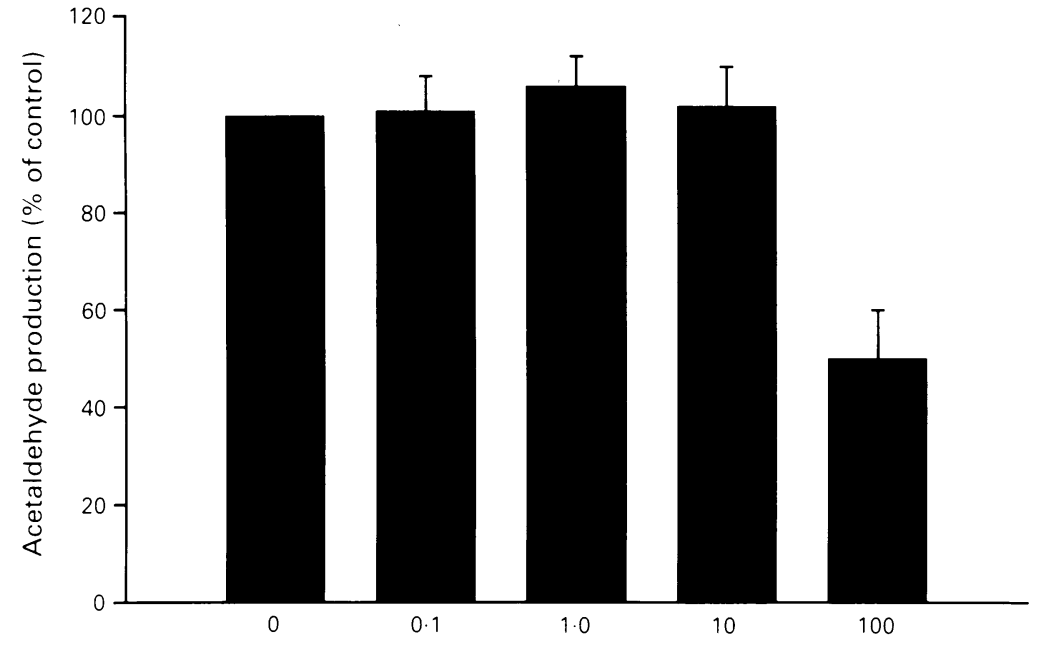

Drug concentration ( $\mathrm{mM}$ )

Figure 4: The effect of 4-methylpyrazole on acetaldehyde formation by colonic contents incubated at $22 \mathrm{mM}$ ethanol at $\mathrm{pH} 9.6$ at $37^{\circ} \mathrm{C}$ for two hours, expressed as percentage (mean (SEM)) of control without the drug.

these phenomena can lead to cellular destruction. In this respect, the probability of alcohol induced organ damage may be proportional to the organ's capacity to metabolise ethanol to acetaldehyde.

Earlier studies have shown that oral ethanol given to rats results in accelerated chemically induced rectal carcinogenesis ${ }^{30}$ and also increased mucosal acetaldehyde concentrations in the descending colon compared with the ascending colon. ${ }^{12}$ This increase in acetaldehyde concentration was paralleled by a significant increase in the number of anaerobic bacteria. ${ }^{12}$ Moreover, rats with a jejunal self filling diverticulum (and consequent bacterial overgrowth) show a noticeable increase in portal acetaldehyde concentrations after intragastric ethanol when compared with controls with a self emptying diverticulum, and incubation of diverticular contents with ethanol leads to fairly high acetaldehyde concentrations. ${ }^{31}$ These findings strongly advocate the role of intestinal bacteria in the oxidation of ethanol to acetaldehyde, which in turn could mediate some of the gastrointestinal toxicity of ethanol in laboratory rats.

The concentrations of ethanol in the ileum after alcohol ingestion are similar to those of the vascular space. ${ }^{32}$ Our results show that human colonic contents are capable of oxidising ethanol to acetaldehyde in vitro at the comparatively low ethanol concentrations known to exist in the colon during normal drinking. Moreover, this acetaldehyde formation takes place at a $\mathrm{pH}$ normally found in the colon, although the production is enhanced by increasing $\mathrm{pH}$. Colonic bacteria could thus provide a clinically significant source of acetaldehyde in the large bowel and this acetaldehyde could possibly lead to toxic changes in the intestinal wall. Resulting cellular injury could then lead to compensatory hyperregeneration, which by itself can favour carcinogenesis. Furthermore, acetaldehyde produced in the intestine and reaching the liver by the portal circulation could also potentiate the hepatotoxicity of acetaldehyde originating in the liver, thus making subjects with certain types of colonic microflora more vulnerable to alcohol induced hepatic injury than others. Acetaldehyde might also have an important role in the pathogenesis of alcohol induced diarrhoea, a well reported, but poorly understood symptom among alcoholics. ${ }^{10} 1133$

In this study we had no opportunity to obtain bacteriological data from the faecal samples and samples were not stored or incubated strictly anaerobically, which may have reduced the ratio of anaerobic/aerobic organisms. The rather large variation seen in the acetaldehyde forming capacity in this study could, therefore, be explained by different bacterial counts, as well as different bacterial viability in the samples. Further studies are, consequently, already in progress in our laboratory to establish the capacity of various colonic bacterial strains to metabolise ethanol to acetaldehyde in vitro.

As described in this paper, colonic acetaldehyde production is rapidly reduced with lowering of the $\mathrm{pH}$. Dietary fibres decrease the $\mathrm{pH}$ of colonic content, ${ }^{3+}$ and also have a protective role against colonic cancer. ${ }^{35} 36$ The mechanism behind this protection could be the reduced colonic acetaldehyde production. Therefore, the possible role of dietary factors in the regulation of colonic $\mathrm{pH}$ as well as in production of acetaldehyde also warrants further studies.

In this study, 4-methylpyrazole showed no inhibition on acetaldehyde formation by the colonic content until at a concentration of $100 \mathrm{mM}$. This finding could reflect poor penetration of 4-methylpyrazole through the bacterial wall or merely, insensitivity of the bacterial alcohol dehydrogenase to the inhibitory effect of 4-methylpyrazole in vitro, as previously speculated in the case of Helicobacter pylori. ${ }^{37}$ Studies on the effect of aldehyde dehydrogenase inhibitors on acetaldehyde production by colonic contents have already started in our laboratory.

The technical assistance of Ms Tuula Heiskanen is gratefully acknowledged. The work was financially supported by grant from the Yrjö Jahnsson Foundation, The Finnish Foundation for Gastroenterological Research, and from the Finnish Foundation for Alcohol Studies.

1 Graham S, Daval H, Rohrer T, Swanson M, Sultz H, Shedd $\mathrm{D}$, et al. Dentition, diet, tobacco and alcohol in the epidemiology of oral cancer. I Natl Cancer Inst 1977; 59: epidemiolo.

2 McCoy GD. A biochemical approach to the etiology of alcohol related cancers of the head and neck. Laryngoscop 1978; 88 (suppl 8): 59-62 (part 2)

3 Wynder EL, Covey LS, Mabuchi K, Muskinski M Environmental factors in cancer of the larynx. Second look. Cancer 1976; 38: 1591-601

4 Tuyns A. Epidemiology of alcohol and cancer. Cancer Re 1979; 39: 2840-3

5 Wynder EL, Mabuchi K. Etiological and environmenta factors in esophageal cancer. $7 A M A$ 1973; 226: 1546-8

6 Schottenfeldt D, Gantt RC, Wynder EL. The role of alcohol and tobacco in multiple primary cancers of the upper digestive svstem, larynx and lung. A prospective study. Prer Med 1974; 3: 277-93.

7 Breslow NE, Enstrom JE. Geographic correlations between cancer mortality rates and alcohol-tobacco consumption in the United States. F Natl Cancer Inst 1974; 53: 631-9.

8 Kono S, Ikeda M. Correlation between cancer mortality Kono S, Ikeda $M$. Correlation between cancer mortality
and alcoholic beverages in Japan. Br $\mathcal{f}$ Cancer 1979; 40:

9 Pollack ES, Nomura AMY, Heilbrun I.K, Stemmerman GN, Green SB. Prospective study of alcohol consumption GN, Green SB. Prospective study of alcohol const

10 Robles EA, Mezey E, Halsted CH, Schuster MM. Effect of ethanol on the motility of the small intestine. Fohms Hopkins Med f 1974; 135: 17-24. 
11 Berenson MM, Avner DL. Alcohol inhibition of rectosigmoid motility in humans. Digestion 1981; 22: $210-5$.

12 Seitz HK, Simanowski UA, Garzon FT, Rideout JM, Peters TJ, Koch A, et al. Possible role of acetaldehyde in ethanolrelated rectal cocarcinogenesis in the rat. Gastroenterology related rectal cocarcir

13 Levitt MD, Doizaki W, Levine AS. Hypothesis: activity of the colonic bacteria influences organ injury from ethanol. Hepatology 1982; 5: 598-600.

14 Miyakawa H, Baraona E, Chang JC, Lesser MD, Lieber CS. Oxidation of ethanol to acetaldehyde by bronchopulmonary washings: role of bacteria. Alcohol Clin Re Exp 1986; 5: 517-20.

15 Pikkarainen PH, Salaspuro MP, Lieber CS. A method for the determination of 'free' acetaldehyde in plasma. Alcoholism 1979; 3: 259-61.

16 Lundquist $F$. The metabolism of alcohol. In: Israel Y, Mardones J, eds. Biological basis of alcoholism. New York: John Wiley, 1971: 1-52.

17 Peters TJ. Ethanol metabolism. Br Med Bull 1982; 38: 17-20.

18 Lamboeuf Y, de Saint Blanquat G, Derache R. Mucosal alcohol dehydrogenase- and aldehyde dehydrogenase-
mediated ethanol oxidation in the digestive tract of the rat. mediated ethanol oxidation in the digesti

19 Julkunen RJK, DiPadova C, Lieber CS. First pass metabolism of ethanol: a gastrointestinal barrier against the systemic toxicity of ethanol. Life Sci 1985; 6: 567-73.

20 Lieber CS, Baraona E, Matsuda Y, Salaspuro $M$ Hasumura Y, Matsuzaki S. Hepatotoxicity of acetaldehyde. In: Begleiter $\mathrm{H}$, ed. Biological effects of alcohol. New York: Plenum, 1980: 397-411.

21 Salaspuro M, Lindros K. Metabolism and toxicity of acetaldehyde. In: Seitz HK, Kommerell H, eds. Alcohol related diseases in gastroenterology. Berlin: Springer-Verlag, 1985: 106-23.

22 Barry RE, Williams AJK, McGivan JD. The detection of acetaldehyde/liver plasma membrane protein adduct
formed in vivo by alcohol feeding. Liver $1987 ; 7: 364-8$.

23 Lin RC, Smith SR, Lumeng L. Detection of proteinacetaldehyde in the liver of rats fed alcohol chronically. f Clin Invest 1988; 81: 615-9.

24 Sillanaukee P, Seppä K, Koivula T. Effect of acetaldehyde on hemoglobin: $\mathrm{HbA}$ as a potential marker of heavy drinking. Alcohol 1991; 8: 377-81.
25 Sillanaukee $P$, Koivula T. Detection of a new acetaldehydeinduced hemoglobin fraction $\mathrm{HbA}_{1 \mathrm{ach}}$ by cation exchange liquid chromatography. Alcohol Alcohol 1990; 6: 842-6.

26 Sorrel M, Tuma D. Hypothesis: alcoholic liver injury and the covalent binding of acetaldehyde. Alcoholism 1985; 9: 306-9.

27 Espina N, Lima V, Lieber CS, Garro AJ. In vitro and in vivo inhibitory effect of ethanol and acetaldehyde on $\mathrm{O}^{6}$-methylguanine transferase. Carcinogenesis 1988; 9, 761-6.

28 Niemelä O, Klajner F, Orrego H. Antibodies agains acetaldehyde modified protein epitopes in human alcoholics. Hepatology 1987; 7: 1210-4.

29 Laskin CA, Vidins E, Blendis L, Solonoka CA Autoantibodies in alcoholic liver disease. Am f Med 1990 89: 129-33.

30 Seitz HK, Czygan P, Waldherr R, Veith S, Raedsch R, Kässmodel H, Kommerell B. Enhancement of 1,2-dimethylhydrazine-induced rectal carcinogenesis following chronic ethanol consumption in the rat. Gastroenterology 1984; 86: 886-91.

31 Baraona E, Julkunen RJK, Tannenbaum L, Lieber CS. Role of intestinal bacterial overgrowth in ethanol production of intestinal bacterial overgrowth in ethanol production and $m$

32 Halsted $\mathrm{CH}$, Robles EA, Mezey E. Distribution of ethanol in the human gastrointestinal tract. Am f Clin Nutr 1973 26: $831-4$.

33 Pirola RC, Davis AE. Effects of intravenous alcohol on the motility of the duodenum and of the sphincter of Oddi. Australas Ann Med 1970; 19: 24-9.

34 Pye G, Crompton J, Evans DF, Clarke AG, Hardcastle JD. Effect of dietary fibre supplementation on colonic $\mathrm{pH}$ in healthy volunteers. Gut 1987; 28: A1366-7.

35 Dales LG, Friedman GD, Ury HK, Grossman S, Williams SR. A case-control study of relationship of diet and other traits to colorectal cancer. Am $f$ Epidemiol 1978; 109: traits to

36 Heilbrun LK, Nomura A, Hankin JH, Stemmermann GN. Diet and colorectal cancer with special reference to fiber intake. Int 7 Cancer $1989 ; 44: 1-6$.

37 Kaihovaara P, Salmela KS, Roine RP, Kosunen TU, Salaspuro $M$. Purification and characterization of Helicobacter pylori alcohol dehydrogenase. Alcoholism (in press). 